A-UR- 93-188:

\section{Title: \\ MEASURED PERFORMANCE OF THE GTA RF SYSTEMS}

$$
\text { ง... } 64
$$

Author(s):

\section{Submitted to:}

1993 Particle Accelerator Conference
Washington, DC

May 16-20, 1993

P. M. Denney and S. P. Jachim

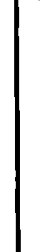

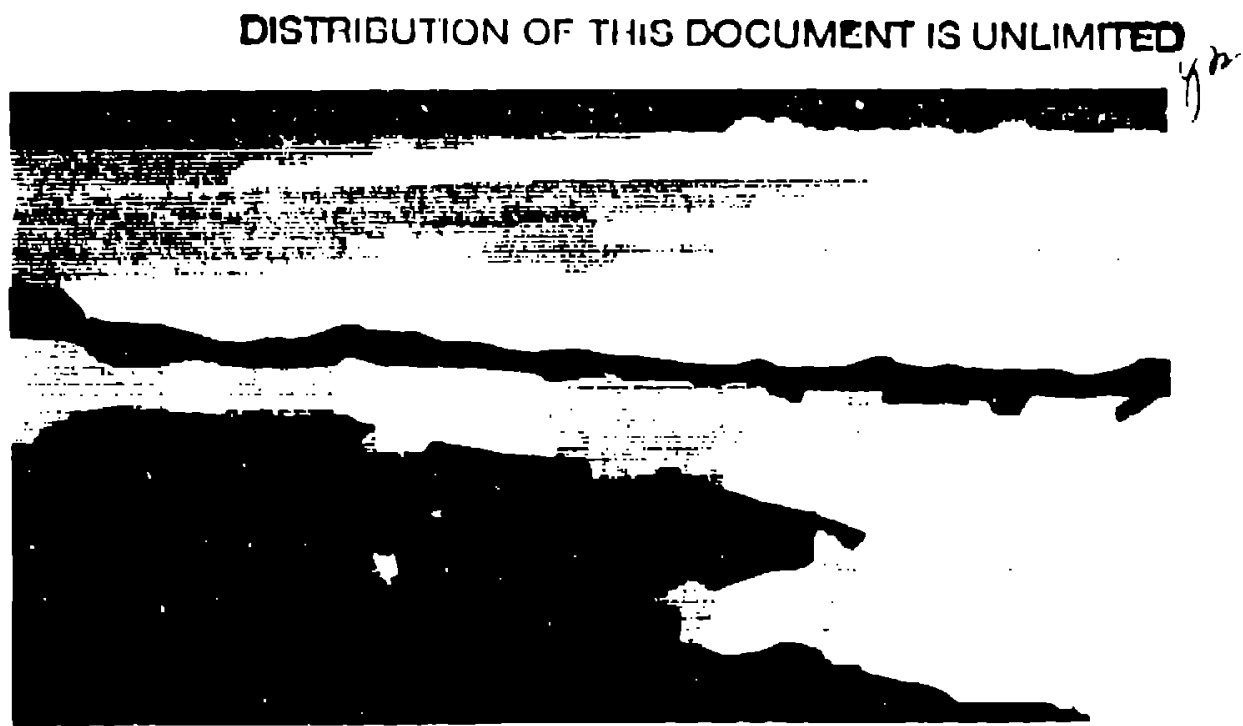




\title{
Measured Performance of the GTA RF Systems*
}

\author{
Peter M. I xenney" and Sikphen P'. Jikchim \\ M1S-11K27. I os Alamos Nallomal I ahoralory. I w Alamos, NM 6754
}

Ahrtrait

This paper describes the performance al due Rl systems on the (iround les Acelerator alitA). The Rl: syblem architcilure is hrielly deserstud. Among the Rl: pertormance results presented are Rl: field llathess and tahilily. amplitude and phate control resolutici, and control system haudwidth and stability. The rejection hy the Rl systems of heaminduced disturbances, such as transicnts and nouse, are allaiyzed. The observed responses are also compiared (1) computer-hatsed simulations of the RF systems for villidation.

\section{INTR()DUCTION}

In resent months. an exp rimest was perfomed on (it'A which resulted in the successful commissioning of the 12 Mi:V alceclerallor [I] The neasured mertornance of the Rfi control systems with and willoult be:un disturhankes will be prescented.

\section{RI: SYSTEM LIESCRIPTION}

Much has bedn wrillen in the literalure regarding the

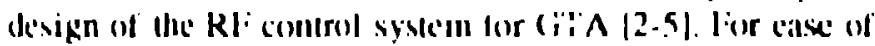
understanding the measurements, however, a hrel cxplanation of important concepts is in order.

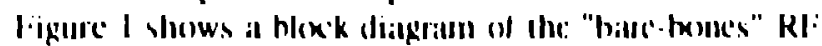
system operallang in slowed loxp comerol. Idditional modules

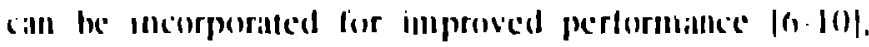
however, llat is beyond the se(upe ol this paper

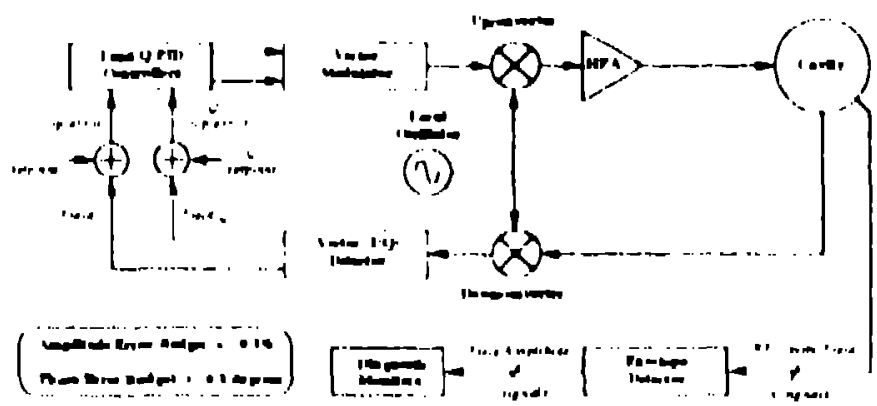

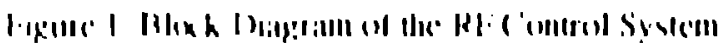

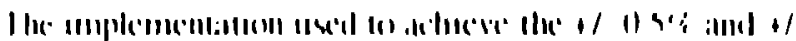

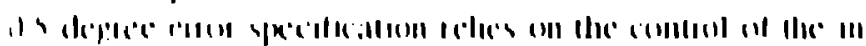

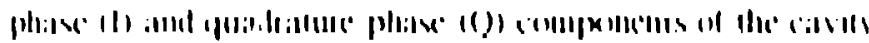

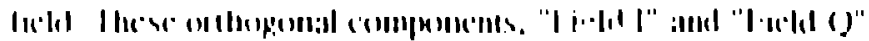

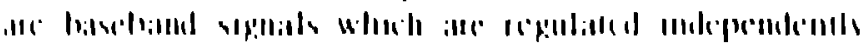

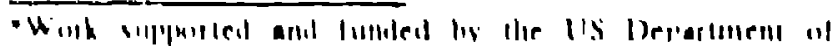

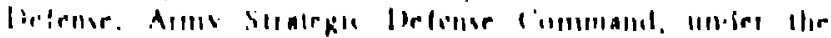

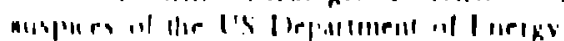

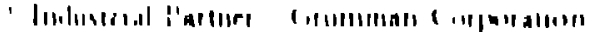

via the I cintroller and 0 ('ontsoller. respectively. Regulatung

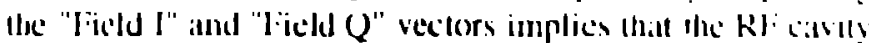

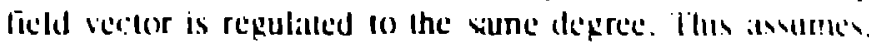

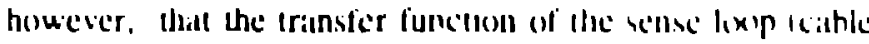

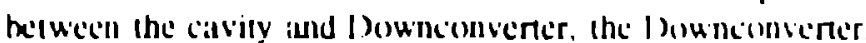
and the Vector Detector) rematlls conscint. Sillse the phase stabiliaed eable has not been implemented thus las |0|. long term phase stability call not the assumed lhos, all the measurements presented in this paper will at lelress slon tem stathility. "The "Field Amplitude" and "I-ield Ph:se:" Slatsilty can be derived using the forowing simple eyuations.

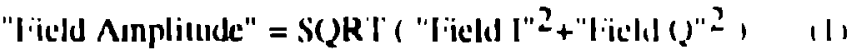

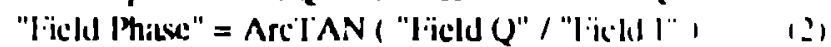

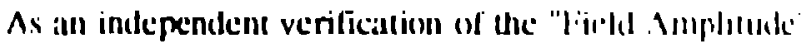
sahility, cavily field signals from varnous pick up lin)p wire meisured by linvelope I eacectors producill. "I ald Amplitude" signals. as well. To avoid comlusmm, henerer.

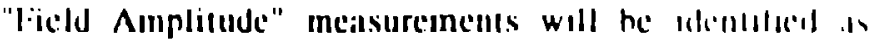
linvelope I xelector or Vector I xelector me:asurements.

\section{TEST RESUII.ISS}

\section{A. Wialeform I): quatation Measurements}

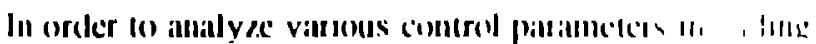
noise rejectlon. a waveform digities wa emplused late

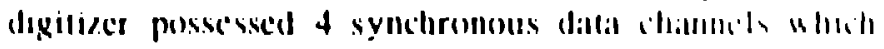

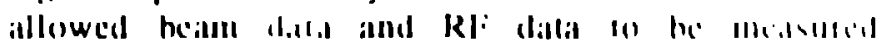

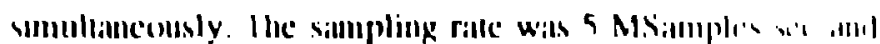

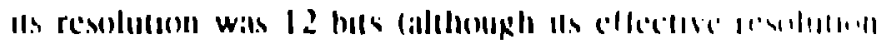

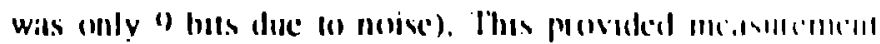

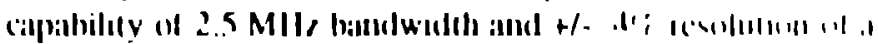

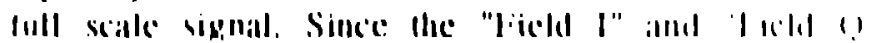

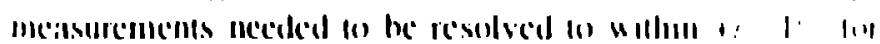

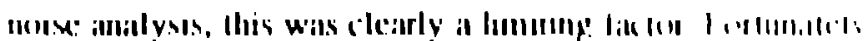

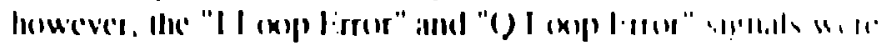

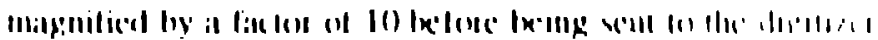

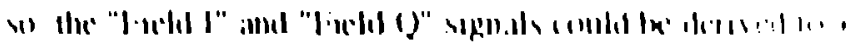

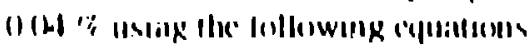

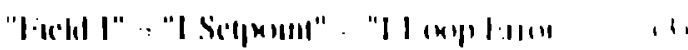

$$
\begin{aligned}
& \text { "I) }
\end{aligned}
$$

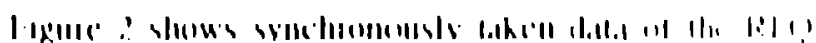

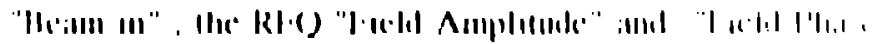

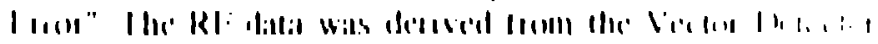

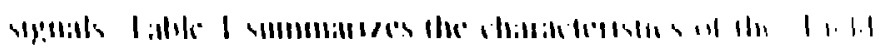

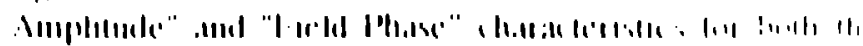

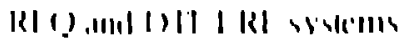




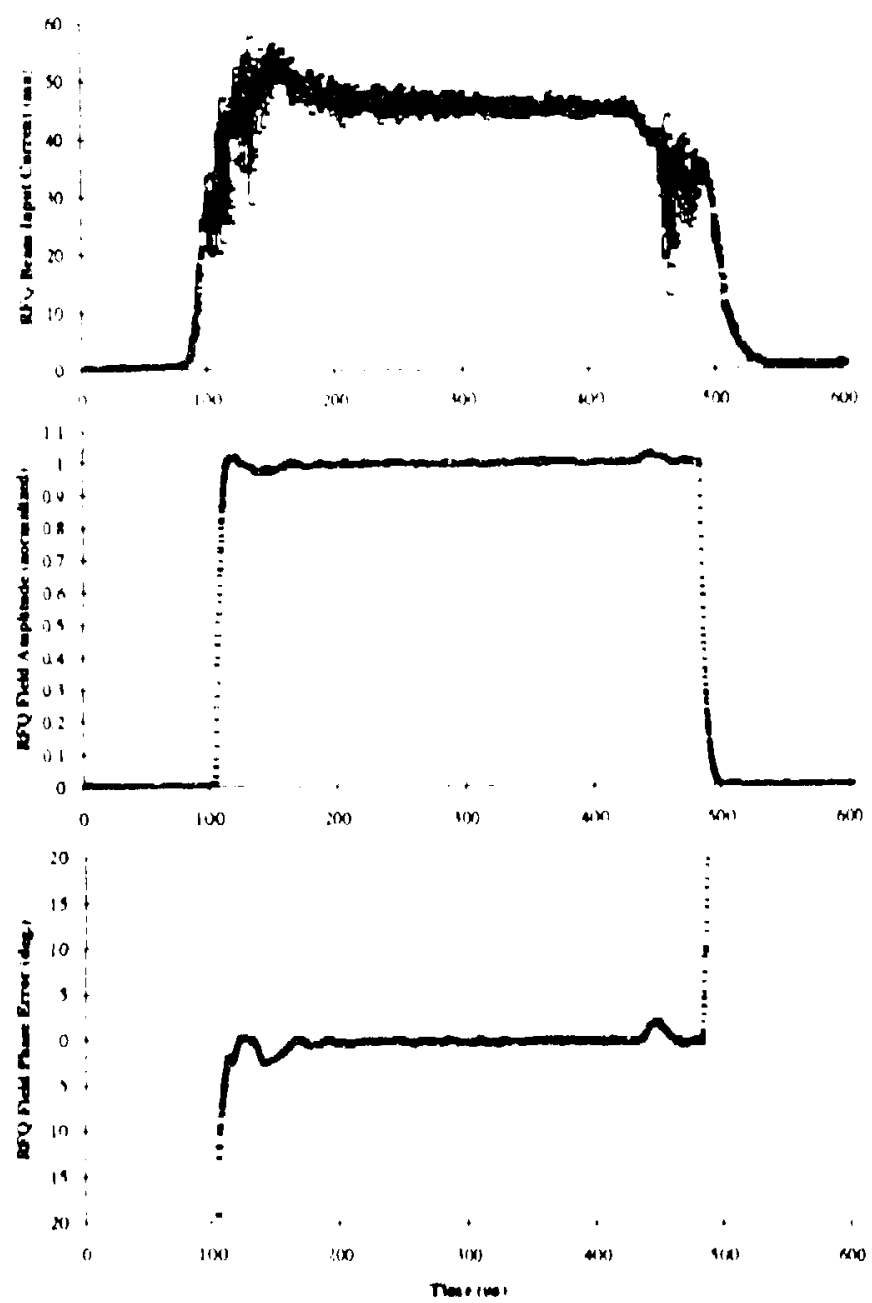

Figure 2. Synchronous Waveforms of the RI:Q "Beam IN" (converted to mit), "lield Amplitude" and "lield Phises".

Tahk I. (haracteristecs of Rl() and I)!T.1 RJ: sysuems

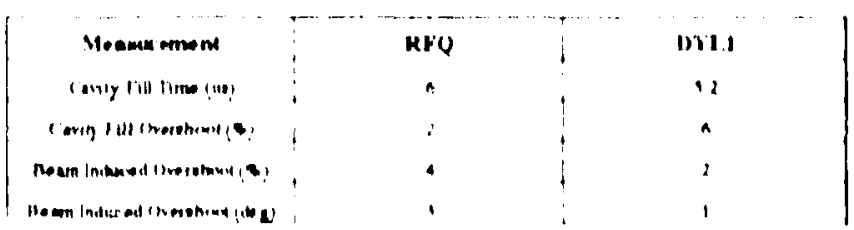

ligure 1 expands the waveforms of figure 2 from $2(x)$.

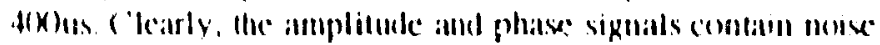
all drequencies of 50 . I(K) KHe. The beam signal cleouly

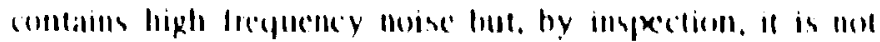

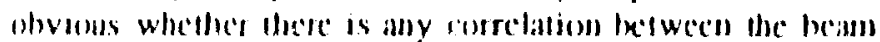
and Rl: Croms spectomen annlysis was performed which

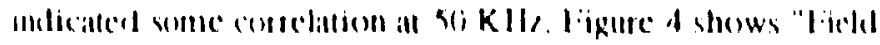
Amplitude" and "lichle lhase listor" waveforms without

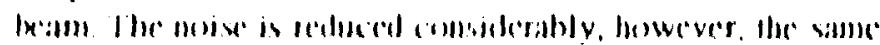

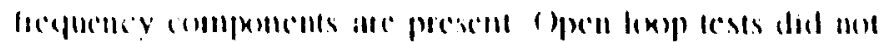

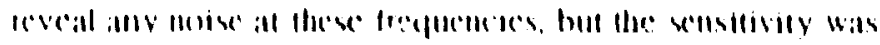

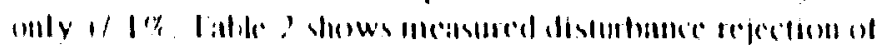

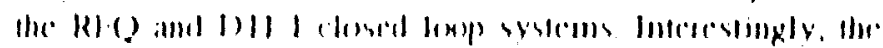

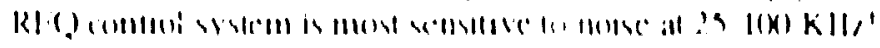
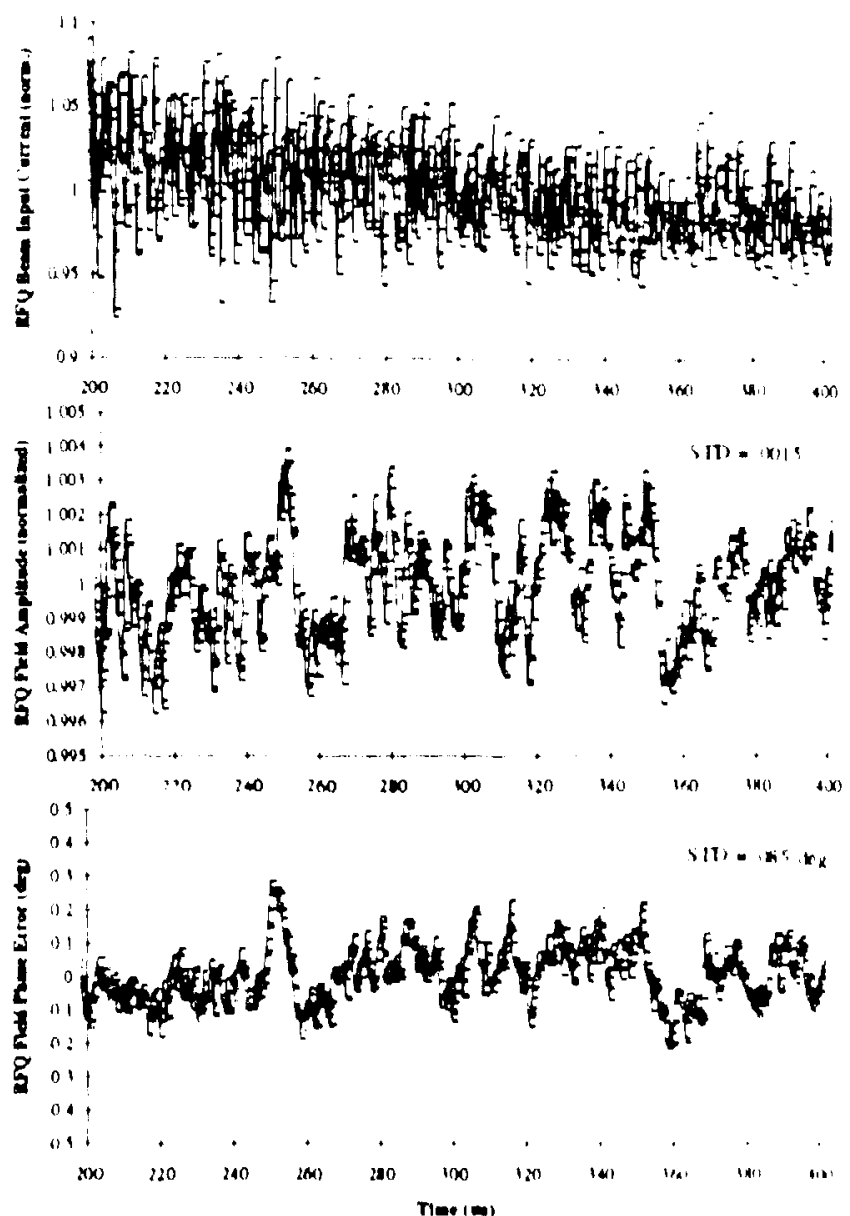

Figure 3. Data from figure 2 expanded from $2(x)-4(x)$ us

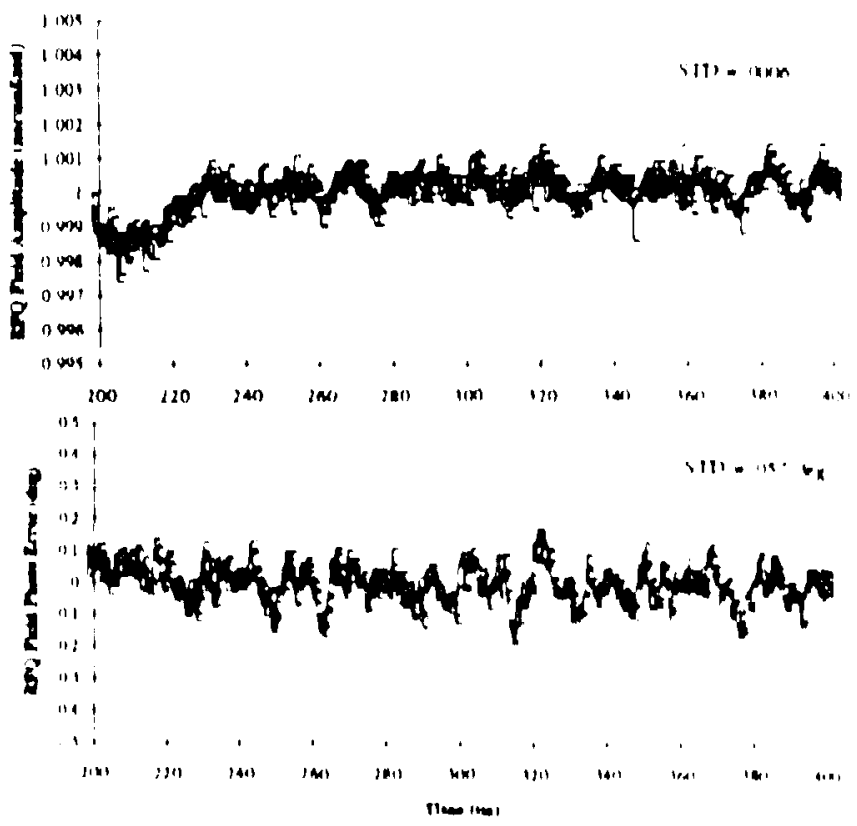

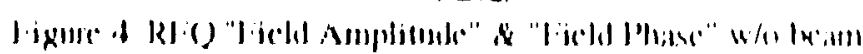

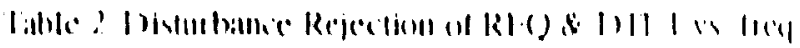

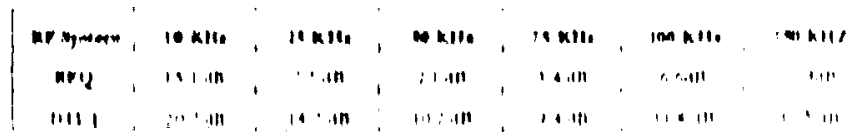


B. Single Sidmple' , Pulse Measurime'nes

liyuipned with 12-hit A'l) converters on the Vector Delector and linselope Delector Modules, the "Iichl I". "I.ield $Q "$, and vierious "I.iclel Amplitude" signal, were sychomously simmplad at a smele punt durme dic Rl: pulse

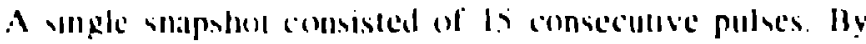

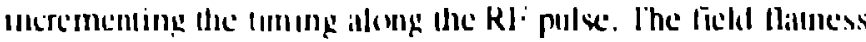
uils measured lipure s show the llithess of the lith I "I:ield Amplitude" without he'iul its incisured from the

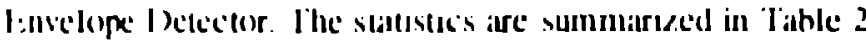

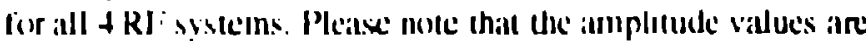
nomialised and the meiln villed are relative to dhe serpoints. Since the l:melope I xecector readlings were normalized to the meinl value, its meall is eyual (o unity. Also, STl) represents standard deviation. Table 3 gives the stitisties a th theam.

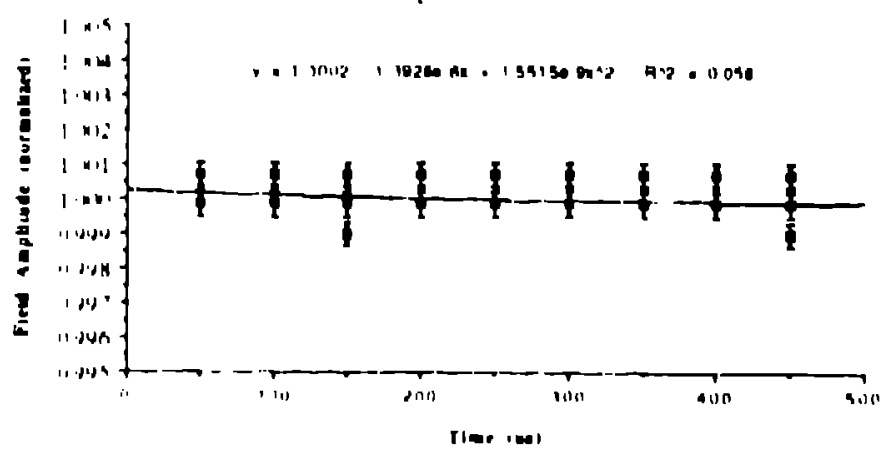

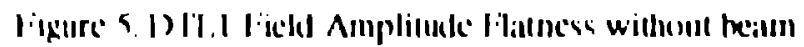

Fialle I. Siallswes of all 4 Rl: syslems willoum be:aln

\begin{tabular}{|c|c|c|c|c|}
\hline & aru & IMISA & IMSA & In I \\
\hline "U Brerclin! & & . & . & . \\
\hline Alnqullitile Mtedri & 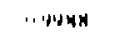 & ים & $1 \cdot 1 ! 1$ & 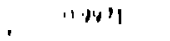 \\
\hline 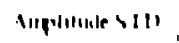 & (.,4n1 & arnini & $1 \cdot 11 ;$ & anuld \\
\hline 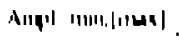 & 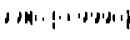 & 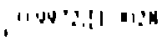 & $|1 \cdot n| l+1 \mid 1 \cdot m_{n} 1$ & $\mid$ \\
\hline 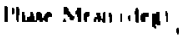 &. & $\cdots 4$ & 11 & 114 \\
\hline I7i,ue $v|l|$ IIIrk & $1,|\times| n$ & 11int & $\||n|$ & 11191 \\
\hline 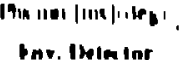 & 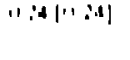 & , "x,pli| & , $114, \mid 1,: 11]$ & ו \\
\hline Anplintule $>111$ & אוירוי & 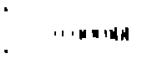 & 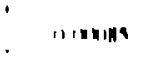 & linntus \\
\hline
\end{tabular}

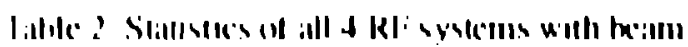

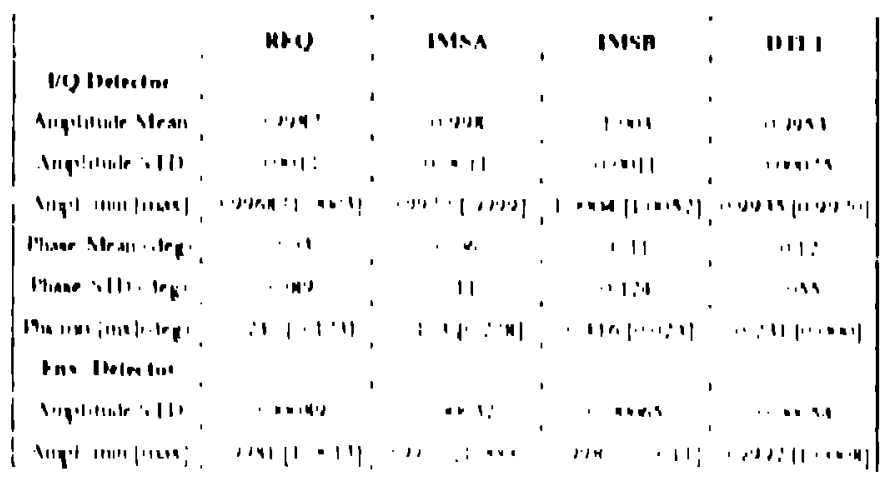

\section{SLMMARY}

Tu summarize, all $\mathrm{Rl}$ : cuntrol syolems excedel the

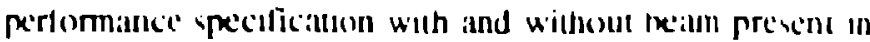
the cavitie's As expedited. the amplitude and phate crorst are greater with hoiun present, however, It is unclear an Io hou

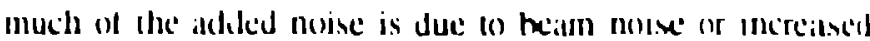
forward $\mathrm{Kl}$ : power. liurther lesting using more alcollsalls

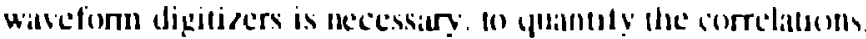
The data presented. however, dearly bow llith the RI.

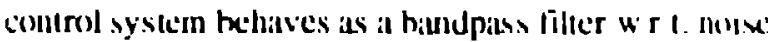

(iend agreement of the standiard deviltions wits nesticed belween the $R l Q Q$ waveform digitization meitisurements and the single siunple / pulse lests. Also, excetlent apresinemt of the standard deviations belween Vectur Detector and

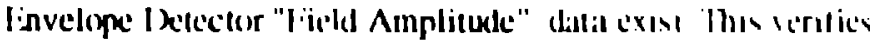
the accuracy of the me:ssurements

\section{AC.KNOWLEDGMENIS}

The authon would like (n) thank the following ind ividuals fur their assistance and patience along the wily: 13 N(kin., h Barr, S. Bowling, R. ('ole, (', (iessik, I) (inlpatrick, M Jenkins, K. Johnson, D). Kersticus, J Power, A Regill, (1 Sinder. B. Weiss, $A$. Young, and (' ' Yiomek:

\section{REFERENCES}

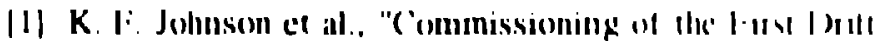

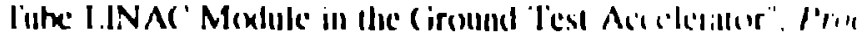

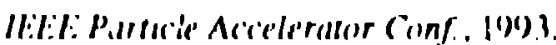

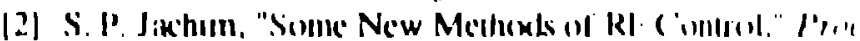
I.INAC (imfl, pp. 573-577. I(x)()

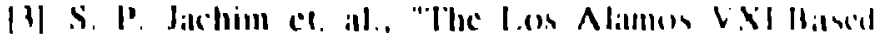

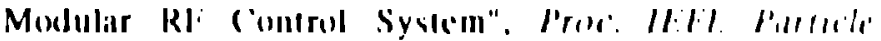
Arielerator (ionf.. $l(x))$

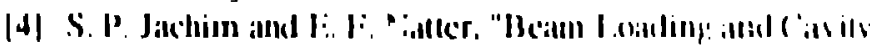

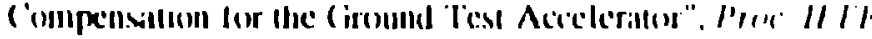

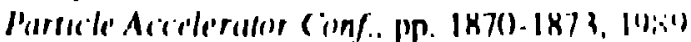

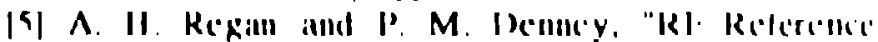

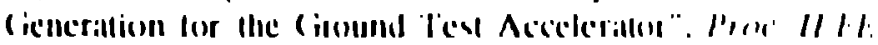

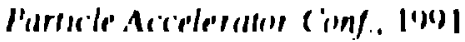

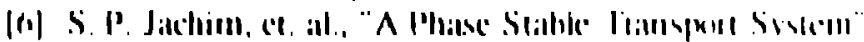

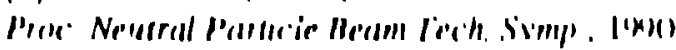

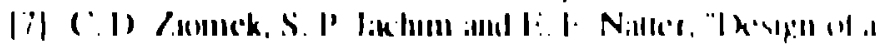

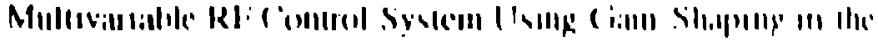

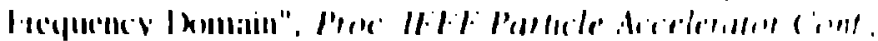

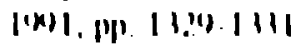

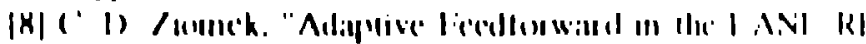

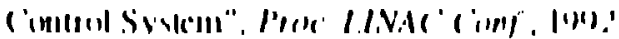

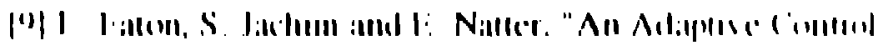

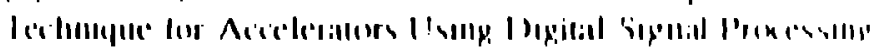

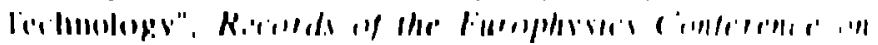

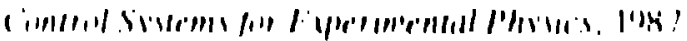

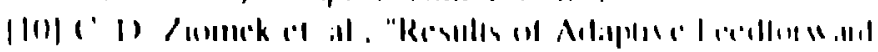

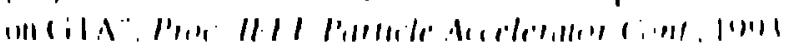

